\title{
Influence of orbital forcing and solar activity on water isotopes in precipitation during the mid- and late Holocene
}

\author{
S. Dietrich ${ }^{1}$, M. Werner ${ }^{1}$, T. Spangehl ${ }^{2}$, and G. Lohmann ${ }^{1}$ \\ ${ }^{1}$ Alfred Wegener Institute for Polar and Marine Research, Bussestr. 24, 27570 Bremerhaven, Germany \\ ${ }^{2}$ Deutscher Wetterdienst, Frankfurter Str. 135, 63067 Offenbach, Germany
}

Correspondence to: S. Dietrich (stephan.dietrich@awi.de)

Received: 27 July 2012 - Published in Clim. Past Discuss.: 17 August 2012

Revised: 27 November 2012 - Accepted: 6 December 2012 - Published: 8 January 2013

\begin{abstract}
In this study we investigate the impact of mid- and late Holocene orbital forcing and solar activity on variations of the oxygen isotopic composition in precipitation. The investigation is motivated by a recently published speleothem $\delta^{18} \mathrm{O}$ record from the well-monitored Bunker Cave in Germany. The record reveals some high variability on multicentennial to millennial scales that does not linearly correspond to orbital forcing. Our model study is based on a set of novel climate simulations performed with the atmosphere general circulation model ECHAM5-wiso enhanced by explicit water isotope diagnostics. From the performed model experiments, we derive the following major results: (1) the response of both orbital and solar forcing lead to changes in surface temperatures and $\delta^{18} \mathrm{O}$ in precipitation with similar magnitudes during the mid- and late Holocene. (2) Past $\delta^{18} \mathrm{O}$ anomalies correspond to changing temperatures in the orbital driven simulations. This does not hold true if an additional solar forcing is added. (3) Two orbital driven midHolocene experiments, simulating the mean climate state approximately 5000 and $6000 \mathrm{yr}$ ago, yield very similar results. However, if an identical additional solar activity-induced forcing is added, the simulated changes of surface temperatures as well as $\delta^{18} \mathrm{O}$ between both periods differ. We conclude from our simulation results that non-linear effects and feedbacks of the orbital and solar activity forcing substantially alter the $\delta^{18} \mathrm{O}$ in precipitation pattern and its relation to temperature change.
\end{abstract}

\section{Introduction}

Numerous European proxy archives demonstrate consistent strong millennial scale climate variability during the mid- and late Holocene (Wanner et al., 2008). Some of these records demonstrate an influence of orbital forcing (e.g. Davis and Brewer, 2009). However, a larger number of records show a high variability on a millennial scale that does not clearly correspond to orbital forcing. Such high frequency is for instance recorded in the calcite oxygen isotope signal of several European speleothems (McDermott et al., 2011). It has been suggested that past changes in solar activity might have influenced the European climate, too (e.g. Shindell et al., 2001). Nonetheless, observed proxy variability and its relation to large-scale Holocene climate changes are not fully understood for many European records, yet.

The signature of the orbital forcing on surface temperatures and other climate variables is quite elaborated upon proxy data (Kim et al., 2004; Leduc et al., 2010; Lorenz et al., 2006), modeling studies (e.g. Lorenz and Lohmann, 2004) as well as theoretical concepts (Laepple and Lohmann, 2009) of past climate changes. For Europe, transient climate simulations for the Holocene show a change in the mean state of the North Atlantic Oscillation/Arctic Oscillation (NAO/AO; Hurrell, 1995) with associated high-latitude temperature and sea ice changes (Lorenz and Lohmann, 2004). This matches results from proxy data and indicates a trend from a more positive phase of the NAO/AO during the mid-Holocene to a more negative one during the late Holocene (Rimbu et al., 2003, 2004). 
The influence of the solar activity on Earth's climate is still under discussion (Gray et al., 2010; Haigh, 1994; Lockwood, 2012; Magny et al., 2004; Wanner et al., 2008). Several reviews on this topic have recently been published (Beer et al., 2006; Gray et al., 2010; Haigh, 2003, 2007; Jager, 2008; Lockwood, 2012; Rind, 2002). A plausible physical mechanism how solar activity might alter the state of the middle atmosphere via UV radiation and how this change is transported to the troposphere is explained by a number of studies (Gray et al., 2010; Ineson et al., 2011; Kuroda and Kodera, 2002; Shindell et al., 2001; Spangehl et al., 2010). These studies conclude that an increase of UV radiation during periods of high solar activity heat the middle atmosphere due to photochemical reactions with stratospheric ozone. This leads to an altered stratospheric circulation that propagates poleand downwards to affect tropospheric jet streams and thus atmospheric circulation on a synoptic scale. As a plausible consequence the studies by Lockwood et al. (2010) and Wolling et al. (2010) found an increase of atmospheric blocking during solar minima that accounts for unusual low temperatures over Europe and simultaneous warming over Greenland, emphasizing that solar activity might trigger climate on a regional scale, only. Further studies (e.g. Martin-Puertas et al., 2012) have shown the occurrence of atmospheric circulation pattern similar to a negative NAO phase during periods with less solar activity.

In this study we investigate the impact of orbital forcing and solar activity on variations of the oxygen isotopic composition (typically expressed as $\delta^{18} \mathrm{O}$ ), which is recorded in many paleoclimate archives. In general it is safe to assume that the stable oxygen isotope composition of most terrestrial proxy archives, e.g. the calcite oxygen isotope signal in speleothems, is controlled by the isotopic composition of the local precipitation. Changes of this composition are related to a variety of factors, such as local temperature changes, variations in the amount of precipitation, the isotopic composition of the evaporated source water and the atmospheric transport from the source to the archive location (Dansgaard, 1964). Limitations on the traditional interpretation of $\delta^{18} \mathrm{O}$ precipitation values as a pure temperature proxy at mid- to high latitudes have been identified in several studies (e.g. Jouzel, 1999; Fricke and O'Neil, 1999).

Our study is motivated by recent findings from the speleothem BU4 (Fohlmeister et al., 2012) from the wellmonitored Bunker Cave in Germany (Riechelmann et al., 2011). The core BU4 is investigated as part of the research work performed by the DFG research unit 668 (DAPHNE, http://www.fg-daphne.de). It has been selected as a typical example of a European $\delta^{18} \mathrm{O}$ record.

In this core, the variations of $\delta^{18} \mathrm{O}$ are interpreted as changes in both surface winter temperature and amount of winter precipitation as a consequence of predominant winter precipitation (Wackerbarth et al., 2010, 2012) as well as kinetic isotope fractionation during calcite growths (Fohlmeister et al., 2012). In summary, more negative $\delta^{18} \mathrm{O}$ values rep- resent warmer and more humid winters, whereas more positive $\delta^{18} \mathrm{O}$ values reflect cold and dry winters. This is counter to the conventional $\delta^{18} \mathrm{O}$ "paleothermometer" intepretation (Jouzel, 1999; Lachniet, 2009). However, it has been found that the Bunker Cave is a sensitive region for investigating atmospheric circulation patterns like the North Atlantic Oscillation (Fohlmeister et al., 2012; Langebroek et al., 2011; Lohmann et al., 2012; Wackerbarth et al., 2012).

Dominating periods in this record that are suggested to represent rather cold and dry winter climate in Central Europe center around $7.5 \mathrm{k}(7500 \mathrm{yr}$ before present), $6 \mathrm{k}, 3.5 \mathrm{k}$, and the Little Ice Age (LIA) around $0.5 \mathrm{k}$ (Fig. 1a). During the mid- and late Holocene, the $\delta^{18} \mathrm{O}$ signal of BU4 seems not to be clearly dominated by the orbital forcing (typically expressed as a change in incoming solar radiation at $65^{\circ} \mathrm{N}$ ). For past solar activity changes, the most recent reconstruction of total solar irradiance (TSI) based on measurements of the cosmogenic isotope ${ }^{10} \mathrm{Be}$ in ice cores (Steinhilber et al., 2012) indicate a possible coherence with the $\delta^{18} \mathrm{O}$ values of BU4 during LIA (Fig. 1b). The reconstructions of TSI and sunspot numbers (Solanki et al., 2004; not shown) show another sequence of solar minima around $5.5 \mathrm{ka}$ that appears similar to the solar minima of the Little Ice Age. However, while the $\delta^{18} \mathrm{O}$ signal of the speleothem record from the Bunker cave seems to correspond to the solar radiation during the LIA, an equivalent correspondence is not detected for the mid-Holocene (Fig. 1c).

Due to these findings from BU4, we focus in this study on three Holocene climate periods: the pre-industrial climate (late Holocene) as well as the mean $5 \mathrm{k}$ and $6 \mathrm{k}$ climate (midHolocene). Although orbital driven insolation changes between $6 \mathrm{k}$ and $5 \mathrm{k}$ are rather small, a strong influence on the $\delta^{18} \mathrm{O}$ signal in Central Europe cannot be excluded a priori. For past solar activity, to our knowledge no investigations of this external forcing on the Holocene $\delta^{18} \mathrm{O}$ signal in precipitation exist, yet. Furthermore, although it is obvious that both external forcing interfere with each other, it is unclear how the combination of them is imprinted in the various continental $\delta^{18} \mathrm{O}$ records.

Our study is based on a set of novel climate simulations performed with the atmosphere general circulation model (AGCM) ECHAM5-wiso. This model is able to simulate the isotopic composition within all compartments of the model's hydrological cycle (Werner et al., 2011). As recently demonstrated by Wackerbarth et al. $(2010,2012)$, the $\delta^{18} \mathrm{O}$ values of precipitation simulated with ECHAM5-wiso can subsequently be used to drive a calcification model to successfully simulate the $\delta^{18} \mathrm{O}$ value of BU4 cave drip water and speleothem calcite. However, in this study we simulate and analyze mean values of $\delta^{18} \mathrm{O}$ in precipitation, only, but with a focus on central Europe. 


\section{Methods and model setup}

In this section we first explain the isotope model we use in this study. Then we present the setup of the model experiments to account for influences of orbital parameters and solar activities as well as the interaction between both. Hereafter, we explain our choice of analyzed climate parameters.

\subsection{ECHAM5-wiso}

We apply the atmospheric general circulation model ECHAM5-wiso that explicitly allows the simulation of the three isotopic water species $\mathrm{H}_{2}^{16} \mathrm{O}, \mathrm{H}_{2}^{18} \mathrm{O}$, and $\mathrm{HDO}$ (Werner et al., 2011). This model has its origin in the fifth version of the atmospheric general circulation model ECHAM5 (Roeckner et al., 2003, 2006) and is enhanced by including a water isotope module in the model's hydrological cycle, following the work of Joussaume et al. (1984), Jouzel et al. (1987), and Hoffmann et al. (1998). The isotope module computes changes of the composition of different water masses within the entire hydrological cycle, including evaporation from the ocean, cloud condensation, precipitation, surface water reservoirs, and river runoff.

Today, only two fully coupled ocean-atmosphere models (AOGCM) with water isotopes exist: The NASA GISS ModelE (Schmidt et al., 2007) and HadCM3 (Tindall et al., 2009). Until now, no fully coupled AOGCM is available that uses the isotope version ECHAM5-wiso. Thus, the model is driven by orbital parameters and greenhouse gas concentrations (GHG). Additionally, mean monthly sea-surface temperatures (SST) and the sea-ice cover (SIC) are prescribed leaving the atmospheric circulation free to evolve. As a further boundary condition, the $\delta^{18} \mathrm{O}$ values of ocean and lake surface waters have to be prescribed. Further values are not prescribed.

In prior studies ECHAM5-wiso has already demonstrated the capability to simulate the present-day isotopic composition of precipitation in good agreement with observational data of the Global Network of Isotopes in Precipitation (GNIP), both on a global (Werner et al., 2011) as well as on an European (Langebroek et al., 2011) scale.

\subsection{Experimental setup}

All ECHAM5-wiso simulations are computed in a high spatial resolution (T106L31) with an approximate horizontal grid size of $1.1^{\circ} \times 1.1^{\circ}$ and 31 vertical layers. All simulations are run for $10 \mathrm{yr}$ after spin-up.

To distinguish between the orbital and solar activity forcing effects on the simulated atmospheric state, we perform two sets of model experiments. A first set contains a standard control simulation under pre-industrial climate conditions (PI) as well as a $5 \mathrm{k}$ and $6 \mathrm{k}$ simulation, each, where only changes of the orbital forcing and greenhouse gases are
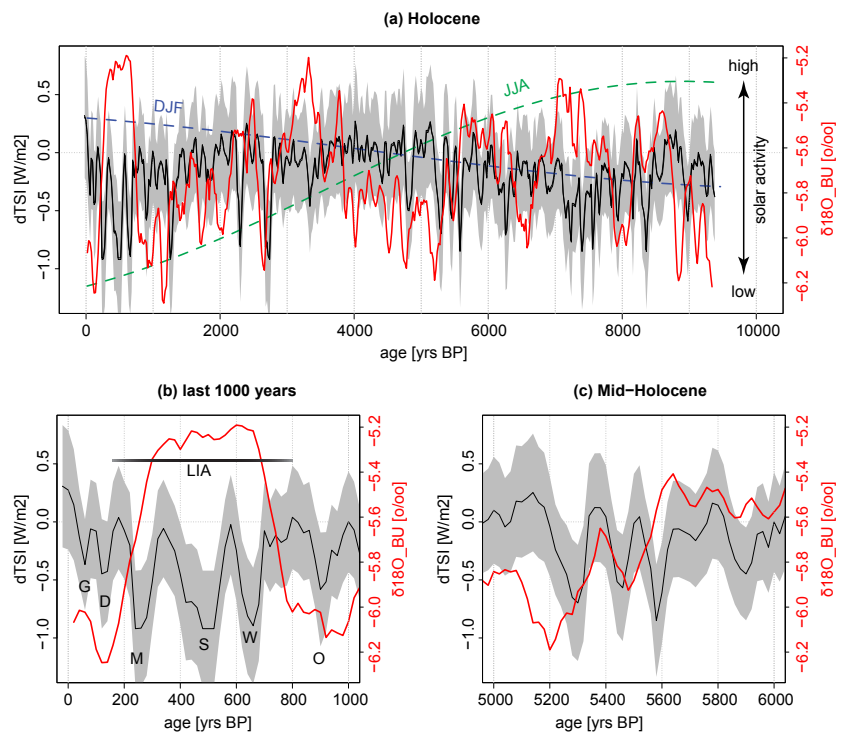

Fig. 1. (a) Reconstructions of solar activity (black) and measured $\delta^{18} \mathrm{O}$ changes of the BU4 record (red) at the Bunker Cave (Germany) during the mid- to late Holocene. The dashed lines show the relative trends of summer (JJA) and winter insolation (DJF) altered by orbital configuration changes. The plot shows the solar activity as the difference of total solar irradiance from the value during the solar cycle minimum of the year $1986 \mathrm{AD}\left(1365.57 \mathrm{Wm}^{-2}\right.$; Steinhilber et al., 2012). Gray bands represent the 1-sigma uncertainty. (b) and (c) same as (a) but focusing on the last $1000 \mathrm{yr}$ and the midHolocene, respectively. Capital letters mark grand solar minima: G: Gleissberg, D: Dalton, M: Maunder, S: Sprorer, W: Wolf, O: Ort.

applied. The second set of simulations additionally accounts for positive and negative changes in the solar activity.

The applied orbital parameters and atmospheric concentrations of greenhouse gases $\left(\mathrm{CO}_{2}, \mathrm{CH}_{4}, \mathrm{~N}_{2} \mathrm{O}\right)$ are given in Table 1. All experiments are computed with a fixed solar constant. The $\delta^{18} \mathrm{O}$ values of the ocean surface waters are set to observed modern values, derived from the global gridded dataset (LeGrande and Schmidt, 2006). The surface waters of large lakes were set to a constant value of $+0.5 \%$. As the oceanic $\delta^{18} \mathrm{O}$ distribution during the mid-Holocene is unknown but most likely very similar to today, identical isotope values of lakes and ocean surface waters are used for all simulations.

Required boundary fields of SST and SIC for the first set of simulations (denoted with the suffix "orb") are derived from a transient Holocene run of the coupled atmosphere-ocean model ECHO-G (Lorenz and Lohmann, 2004). For the three time slices PI, $5 \mathrm{k}$ and $6 \mathrm{k}$ climatological means were calculated using 50 model years. Since this ECHO-G experiment was run with an orbital acceleration factor of 10 (see Lorenz and Lohmann, 2004, for details), every 50-yr period represents 500 calendar years. The three selected ECHO-G periods are listed in Table 1. From these ECHO-G SST and SIC fields the anomalies $5 \mathrm{k}$-PI and $6 \mathrm{k}$-PI were calculated. 
Table 1. Orbital (eccentricity, obliquity, perihelion) and greenhouse gas $\left(\mathrm{CO}_{2}, \mathrm{CH}_{4}, \mathrm{~N}_{2} \mathrm{O}\right)$ forcing of the three periods investigated. Boundary conditions were derived from a transient simulation with the AOGCM ECHO-G (Lorenz and Lohmann, 2004). The used specific model years from this experiment are given in the last column.

\begin{tabular}{llllllll}
\hline & Ecc. & Obl. & Perihel. & $\mathrm{CO}_{2}$ & $\mathrm{CH}_{4}$ & $\mathrm{~N}_{2} \mathrm{O}$ & ECHO-G \\
\hline PI & 0.016804 & 23.04725 & 278.734 & 280 & 760 & 270 & $1926-1976$ \\
5 k_orb & 0.018424 & 24.0239 & 197.594 & 275 & 650 & 260 & $1446-1496$ \\
6 k_orb & 0.018682 & 24.1048 & 180.918 & 280 & 650 & 270 & $1346-1396$ \\
\hline
\end{tabular}

The anomalies were added to mean pre-industrial SST and SIC fields (observational period: 1870-1899) derived from an AMIP2 climatology (Taylor et al., 2000) to avoid any ECHO-G related model bias in the prescribed mean state of SST and SIC.

To account for solar induced effects originating in the stratosphere a second set of ECHAM5-wiso simulations is performed. This time, the according SST and SIC boundary fields are derived from a transient simulation of the last 500 years performed with the EGMAM model (ECHO-G with Middle Atmosphere Model; Spangehl et al., 2010). This transient simulation (denoted as EGMAM2 in Spangehl et al., 2010) is driven by changes in total solar irradiance due to solar activity as well as volcanic eruptions and changes in greenhouse gas concentrations. It includes changes in shortwave heating due to prescribed photochemical changes in ozone in the stratosphere. For our study, we selected two time slices from this EGMAM transient simulation: one with a rather low solar irradiance, denoted as sol( -$)$, and one with a rather high solar irradiance, denoted as sol(+). For the sol(-) case climatological means are calculated for the time slice 1675-1715 AD, covering the late Maunder Minimum as defined by Spangehl et al. (2010). The sol(+)-boundary conditions were calculated from the years 1750-1790 AD of the EGMAM simulation, respectively. Both chosen time periods have an almost equal, nearly constant $\mathrm{CO}_{2}$ level. The SST and SIC anomalies of the sol(-) and sol(+) time slices are calculated as the deviation from the arithmetic mean state of sol( -$)$ and sol $(+)$. These anomaly fields are then combined with the PI, $5 \mathrm{k}$ and $6 \mathrm{k} \mathrm{SST}$ and SIC fields from the first set to account for the additional forcing due to low (high) solar activity. These ECHAM5-wiso experiments are denoted with the suffix "sol(-)" and "sol(+)", respectively.

In summary, we compute and analyze nine ECHAM5wiso simulations to study the orbital and solar activity forcing effects on the mid- and late Holocene climate: PI, 5 k_orb, 6 k_orb, PI_sol(-), 5 k_sol(-), 6 k_sol(-), PI_sol(+), $5 \mathrm{k} \_$sol $(+)$and $6 \mathrm{k} \_s o l(+)$.

In our analyses we focus on modeled surface temperatures as one of the key paleoclimate variables, and $\delta^{18} \mathrm{O}$ of precipitation, which is recorded in many paleo archives. If not stated otherwise, all changes are reported as anomalies compared to the pre-industrial control simulation (PI). Thus, statements about depletion of isotopic values or cooler tem- peratures should always be interpreted as relatively depleted values in the isotopic composition or relatively cooler temperatures in the past as compared to the PI simulation.

\section{Results}

In the first three sections of this chapter, we examine the simulated annual mean climate of our various experiments. First, we present the influence of changed orbital forcing for the investigated different Holocene periods. Next, we analyze the influence of solar activity on the late and mid-Holocene climate. In the third section, we study the combined influence of orbital and solar activity forcing on mean annual surface temperatures and $\delta^{18} \mathrm{O}$ in precipitation. Since it is suggested that the $\delta^{18} \mathrm{O}$ signal in European speleothems is dominated by winter climate (Wackerbarth et al., 2010, 2012), the simulated influence of winter (DJF) versus summer (JJA) climate on $\delta^{18} \mathrm{O}$ in precipitation is briefly presented in the last section of this chapter.

\subsection{Influence of orbital forcing on surface temperatures and $\delta^{18} \mathrm{O}$}

For the pre-industrial control simulation (PI), surface temperatures as well as $\delta^{18} \mathrm{O}$ of precipitation are characterized by strong meridional gradients. Warmest temperatures (Fig. 2a) and most-enriched $\delta^{18} \mathrm{O}$ values (Fig. 3a) are found in the tropics, while coolest temperatures and strongest $\delta^{18} \mathrm{O}$ depletion occur in the polar regions. The PI simulation shows a corresponding pattern of temperature distribution and $\delta^{18} \mathrm{O}$ values, indicating a strong dependence of $\delta^{18} \mathrm{O}$ to local temperatures. Focusing on the European continent, a west-east gradient of decreasing $\delta^{18} \mathrm{O}$ values can be observed.

Both mid-Holocene experiments show similar patterns, indicating that orbital driven climate changes between $6 \mathrm{k}$ and $5 \mathrm{k}$ are not very large, neither on a global nor European scale. In general, a change to mid-Holocene orbital parameters with higher contribution of the obliquity-related part of incoming solar insolation results in high-latitude warming and lowlatitude cooling (Fig. 2b and c). This is resembled by enrichment of $\delta^{18} \mathrm{O}$ in high latitudes and depletion in the tropics, respectively (Fig. 3b and c). However, even if most parts of the high latitudes are warming, some spatial heterogeneity is detected; e.g. the Labrador Sea as well as the region south 
of Greenland show some cooling and thus $\delta^{18} \mathrm{O}$ depletion. In addition, the longitudinal temperature gradient in Central Russia is slightly enhanced during $5 \mathrm{k}$ in comparison to $6 \mathrm{k}$. In both mid-Holocene time slices orbital forcing results in distinct cooling patterns south of the Sahel zone and over India as well as Southeast Asia.

This can be related to a meridional shift of the Intertropical Convergence Zone (ITCZ) that is here inferred from the temperature anomalies (Fig. 2). The mid- to late Holocene trend is characterized by a continuous southward migration of the ITCZ caused by the precessional component of orbital insolation forcing (Herold and Lohmann, 2009; Fleitmann et al., 2003; Haug et al. 2001) .

Over Europe, the temperature response due to the changed orbital forcing is less than $+2{ }^{\circ} \mathrm{C}$ for the mid-Holocene. Changes in $\delta^{18} \mathrm{O}$ are on average quite small (less than $\pm 1 \%$ ) and for most regions no substantial change can be observed. Central Europe is, however, partly characterized by higher values, whereas Scandinavia and Morocco is depleted in $\delta^{18} \mathrm{O}$.

\subsection{Influence of solar forcing on surface temperatures and $\delta^{18} \mathrm{O}$}

First, we analyze the PI simulation. To evaluate the influence of changing solar activity on the pre-industrial climate the following two PI simulations are examined: (1) PI_sol(-) takes into account a negative solar forcing and thus resembles similar conditions as during the Maunder Minimum. (2) PI_sol(+) represents a (hypothetical) counterpart of PI_sol(-) with an equivalent, but positive solar forcing. To isolate the solar effect on temperature and $\delta^{18} \mathrm{O}$, we calculate the anomalies induced by the assumed changed solar activity between corresponding simulations, e.g. PI_sol(+)-PI.

Negative solar forcing during the PI climate leads to decreasing annual mean temperatures especially at mid- to high northern latitudes (Fig. 4a). In particular the polar regions south of Greenland, the Labrador Sea, the Barents Sea, the Sea of Okhotsk, and the Hudson Bay are affected by the negative solar forcing. This results in substantially reduced annual mean temperatures with a local cooling of up to $-2{ }^{\circ} \mathrm{C}$. However, sol(-) forcing also results in increased annual mean temperatures over Europe, North America, and parts of Western Siberia. Conversely, a positive solar forcing sol(+) leads to slightly increasing temperatures with a maximum warming of around $+1{ }^{\circ} \mathrm{C}$ (Fig. 4b).

Interestingly, the sol(+) and sol(-) results are not completely opposite to each other, neither spatially nor in absolute temperature anomalies (Fig. 4), although the applied SST forcing setup has been symmetrical. The cooling driven by the sol( $(-)$ forcing is much higher than the response of warming due to sol $(+)$ forcing. This can be in particular observed in the North Atlantic and the Labrador Sea. The effect on low latitude temperature changes is in both cases rather small. For Europe, the sol(-) and sol(+) conditions lead to

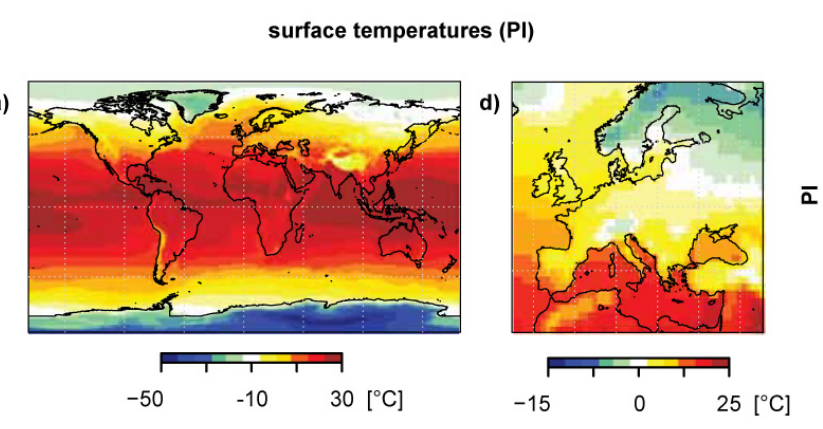

orbital forced surface temperature anomalies (5k \& 6k) b)

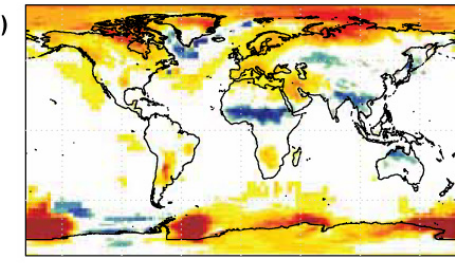

c)

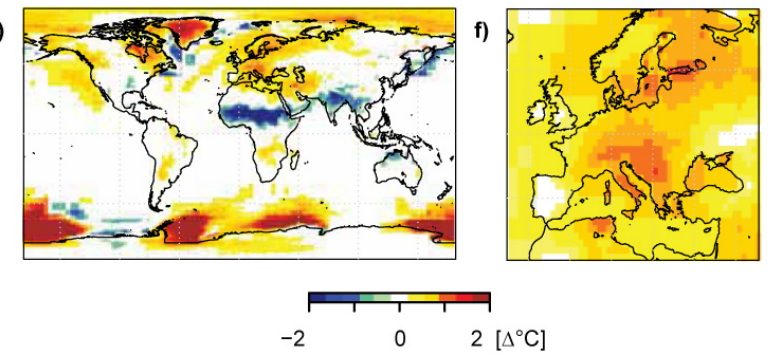

e)

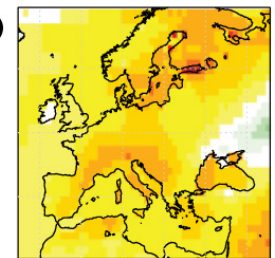

$\overline{2}$
1
옿
01
눈
Fig. 2. Upper row: simulated surface temperature for the preindustrial climate simulation (PI). Middle and lower row: simulated temperature anomalies for both orbital-driven experiments of the mid-Holocene (5 k_orb, 6 k_orb) as compared to the PI simulation. Anomaly values with less than 0.5 of the standard deviation are shaded in white. The right column shows the results for Europe, enlarged.

cooler and warmer surface temperatures in Scandinavia, respectively. Furthermore, we observe a unique warming over western Europe and a slight cooling at the Carpathians in the sol(+) experiment.

The solar forcing effect on the PI distribution of $\delta^{18} \mathrm{O}$ in precipitation does result in a rather noisy anomaly pattern with no clear trend (Fig. 5). The isotope anomalies are in most regions around $\pm 1 \%$ and a clear temperature influence is only observed in the PI_sol(-)-simulation. Here, the strong cooling of the polar regions correlates with more depleted $\delta^{18} \mathrm{O}$ values in precipitation. Over Europe, the $\delta^{18} \mathrm{O}$ changes (Fig. $5 \mathrm{c}$ and d) are quite similar for both experiments and do not reflect the European temperature anomalies (Fig. $4 \mathrm{c}$ and d).

Next, we analyze the two mid-Holocene simulations. Again, to isolate the effects by changing solar activity during the mid-Holocene anomalies are calculated between the 


\section{$\delta^{18} \mathrm{O}$ in precipitation (PI)}

a)
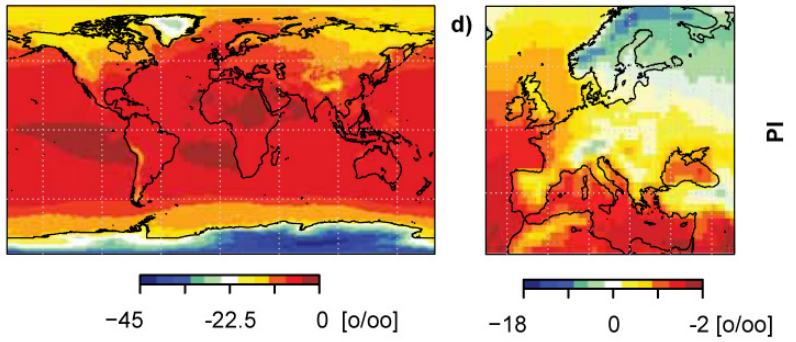

orbital forced $\delta^{18} \mathrm{O}$ anomalies $(5 \mathrm{k} \& 6 \mathrm{k})$ b)
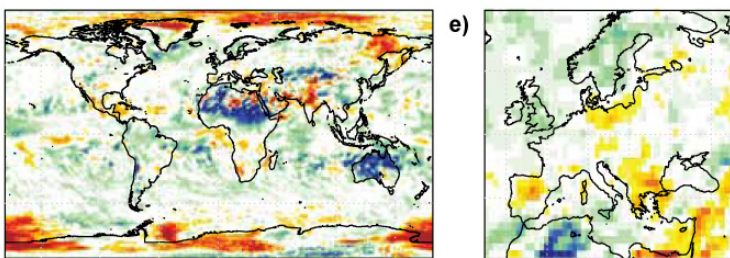

c)

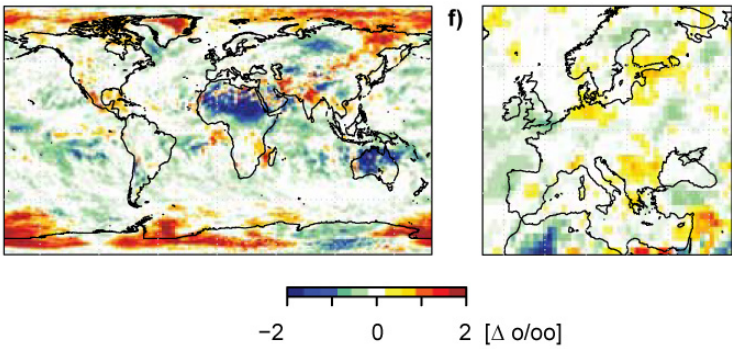

Fig. 3. Same as Fig. 2 but for $\delta^{18} \mathrm{O}$ in precipitation values.

experiment with additional solar influences boundary conditions and with out for each time slice, e.g. $5 \mathrm{k} \_s o l(-)-5 \mathrm{k} \_$orb.

Negative solar forcing, sol(-), leads to decreasing annual mean temperatures especially at mid- to high northern latitudes, both at $5 \mathrm{k}$ and $6 \mathrm{k}$ (Fig. $6 \mathrm{a}$ and b). However, in both time slice simulations a few areas are characterized by slight warming. On a global scale most patterns of temperature anomalies are similar to the findings of the PI simulations (Fig. 4a), e.g. the additional cooling south of Greenland. However, some major differences exist, too, for instance over Europe. In comparison to the PI_sol(-)-simulation (Fig. 4c) the cooling over Europe is stronger in the mid-Holocene simulations (Fig. 6c and d). Nevertheless, a consistent anomaly pattern is observed in all three simulations with a strong temperature decrease in Eastern Europe and Scandinavia as well as no temperature changes (or even a slight warming) in Central Europe. For the simulated mid-Holocene changes in $\delta^{18} \mathrm{O}$, we find on a global scale (Fig. 7a and b) a similar anomaly pattern as for the PI simulation (Fig. 5a), but like for the surface temperatures, regional, differences exist. In parts of Europe, the simulated small isotopic changes in the $5 \mathrm{k}$ a)
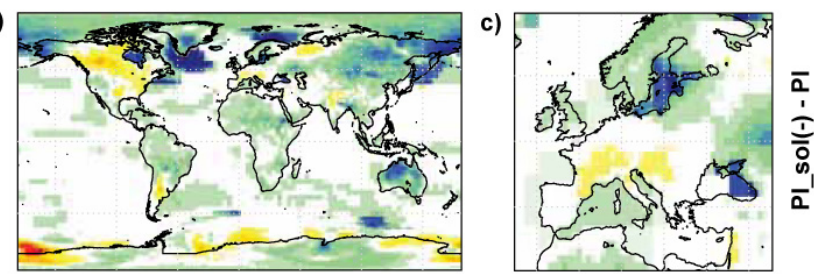

b)

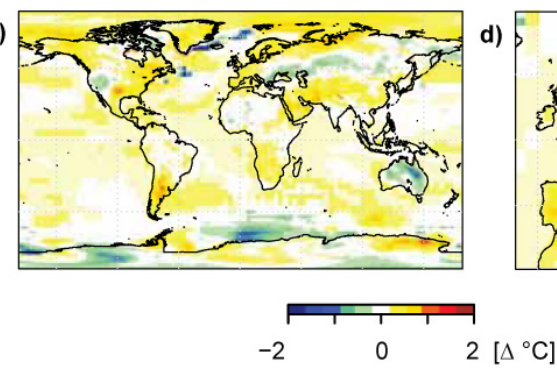

Fig. 4. Simulated solar activity-induced changes of PI surface temperatures. The temperature anomalies are calculated between the experiment with additional solar influence boundary conditions (PI_sol(-) and PI_sol(+), respectively) and the undisturbed PI climate simulation. Plot details are similar to Fig. 2.

and $6 \mathrm{k}$ simulation often disagree and even switch between depletion and enrichment (Fig. 7c and d).

Similar behavior as for the sol(-) experiments exists for the sol(+) forcing results. Again, on a global scale the temperature and $\delta^{18} \mathrm{O}$ anomaly pattern are similar between $6 \mathrm{k}$ and $5 \mathrm{k}$ (Figs. 6e, $\mathrm{f}$ and 7e, f). However, most regions of Europe are affected by slightly increased temperature during $5 \mathrm{k}$ (Fig. 6g), whereas an increased solar forcing during $6 \mathrm{k}$ leads to slight cooling of Eastern Europe (Fig. 6h). For the isotopic composition of precipitation in Central Europe, a depletion of $\delta^{18} \mathrm{O}$ in the $5 \mathrm{k}$ simulation (Fig. $7 \mathrm{~g}$ ) and an enrichment of $\delta^{18} \mathrm{O}$ in the $6 \mathrm{k}$ experiment (Fig. $7 \mathrm{~h}$ ) occur.

\subsection{Combined influence of orbital and solar forcing on surface temperatures and $\delta^{18} \mathrm{O}$}

In this section we present the simulated surface temperatures and $\delta^{18} \mathrm{O}$ of precipitation values of the ECHAM5-wiso simulations that were forced by SST and SIC changes induced by the combination of orbital parameter and solar activity variations.

For both the $5 \mathrm{k}$ and $6 \mathrm{k}$ simulations, an assumed additional increase (decrease) of solar activity leads to an amplification (weakening) of the orbital temperature response during the mid-Holocene (Fig. 8, as compared to Fig. 2). The obliquity driven global temperature anomalies with cooling in the tropics and warming at high latitudes during the midHolocene are preserved in both scenarios. In the sol(-) case the meridional temperature gradient is reduced due to the solar activity-induced cooling. In particular the polar regions 


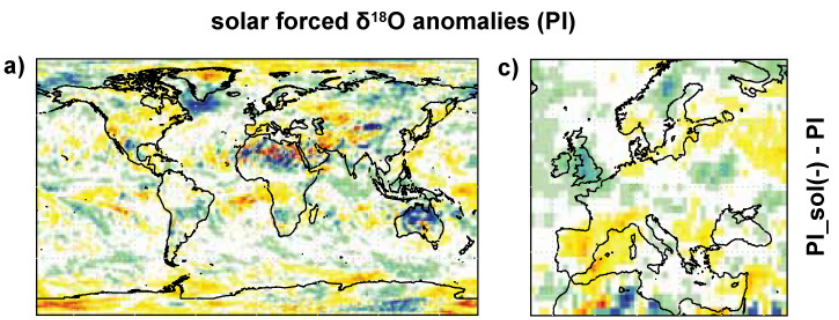

b)

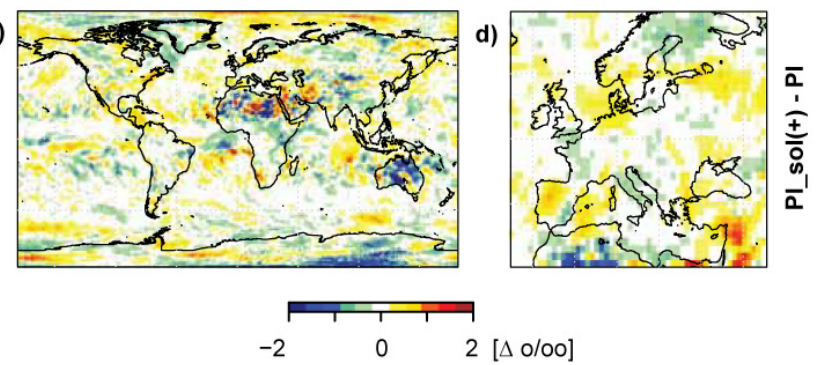

Fig. 5. Same as Fig. 4 but for $\delta^{18} \mathrm{O}$ in precipitation values.

south of Greenland, the Labrador Sea, the Barents Sea, the Sea of Okhotsk, and the Hudson Bay are influenced by the additional forcing. In the sol(+)case the combined forcing leads to further increased temperatures, especially on the Northern Hemisphere. A warming of similar strength, but less geographical expansion is observed for the Southern Hemisphere with highest temperature anomalies over South America and South Africa. For the tropical and subtropical regions, the orbital driven shift of the ITCZ is not substantially affected by any additional solar activity-induced forcing. For Europe, we find for both $\operatorname{sol}(-)$ and $\operatorname{sol}(+)$ cases a warming of Western and Central Europe, which can be related to the dominating orbital forcing in these areas (Fig. 8c, $\mathrm{d}, \mathrm{g}, \mathrm{h})$. However, in Scandinavia and Eastern Europe the regional cooling due to a negative solar-activity induced forcing dominates over the orbital-induced warming, and the combined effect results in PI-similar temperatures during $6 \mathrm{k}$ and a slight cooling of approx. $-1{ }^{\circ} \mathrm{C}$ relative to PI during $5 \mathrm{k}$.

In comparison to the experiments forced by orbital parameter changes, only, an additional solar activity-induced forcing has regionally a high potential to alter the distribution of $\delta^{18} \mathrm{O}$ in precipitation (Fig. 9, as compared to Fig. 3). The global meridional trends from more negative values in low to mid- latitudes to increased values in high latitudes that correspond to the obliquity driven temperature evolution during the Holocene (Sect. 3.1) is regionally disturbed by the additional solar activity-related forcing. For Western Europe, an assumed decrease in solar activity leads to an enrichment in $\delta^{18} \mathrm{O}$ in precipitation during both $5 \mathrm{k}$ (Fig. 9c) and $6 \mathrm{k}$ (Fig. 9d) as compared to the simulation with orbital-induced forcing (Fig. 3e), only. However, an equivalent depletion is not detected for the related sol(+) simulations (Fig. 9g and h). Neither for increase nor decreased solar activity, the simulated European $\delta^{18} \mathrm{O}$ anomalies (Fig. 9c, d, g, h) can be clearly linked to corresponding simulated surface temperature anomalies (Fig. 8c, d, g, h).

\subsection{Relative influence of winter versus summer climate on $\delta^{18} \mathrm{O}$}

Cave monitoring and speleothem analyses suggest that Northern Hemisphere winter is the dominating season for leaving an imprint in the isotopic composition of the precipitated calcite at Bunker Cave (Wackerbarth et al., 2010; Fohlmeister et al., 2012). Analyses of our simulation results reveal that the additional solar activity-induced forcing is not only affecting annual mean climate conditions during the mid- and late Holocene, but that these changes strongly differ with season. The largest part of the Northern Hemisphere temperature changes found in the analyses of annual mean values can be traced back to the simulated winter (DJF) temperatures while the summer season (JJA) shows minor temperature changes (Fig. 10a and b). As for the annual mean values, an asymmetric behavior of the sol $(-)$ and $\operatorname{sol}(+)$ simulations is also observable during winter season: low solar activity has a much stronger influence on Northern Hemisphere winter temperatures than an equivalently high solar activity. The simulated seasonal change of $\delta^{18} \mathrm{O}$ in precipitation shows the strongest link to seasonal temperature changes between $30^{\circ} \mathrm{N}-70^{\circ} \mathrm{N}$. For the winter season, a slight zonal decrease in $\delta^{18} \mathrm{O}$ of approximately $-0.5 \%$ o can be seen for the winter season in the case of decreased solar activity (Fig. 10c). However, the equivalent enrichment of $\delta^{18} \mathrm{O}$ is absent for an assumed equal increase in solar activity. For the Northern polar regions above $70^{\circ} \mathrm{N}$, the ECHAM5-wiso simulations result in an ambiguous pattern of zonal $\delta^{18} \mathrm{O}$ changes. Isotope anomalies are of similar magnitude for both winter and summer season (Fig. 10c and d) and no clear correspondence to the modeled temperature changes can be detected.

For Europe, the simulated winter $\delta^{18} \mathrm{O}$ anomalies (Fig. 11) are in many regions similar to the annual mean ones (Figs. 5 and 9) but strengthened in magnitude. This complies with a stronger general influence of winter versus summer changes on the annual mean climate in Europe. As for the annual mean, the wintertime $\delta^{18} \mathrm{O}$ patterns over Central Europe are rather noisy with many small-scale regions of isotope enrichment and depletion that cannot be clearly linked to winter temperature changes (not shown). Again, an assumed strengthening or weakening of solar activity does not result in equivalent isotope anomalies, neither for the PI nor the $5 \mathrm{k}$ and $6 \mathrm{k}$ simulations. 
solar forced surface temperature anomalies (5k \& 6k)

a)

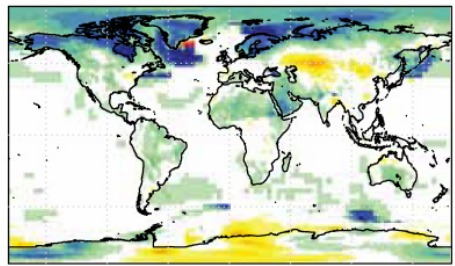

b)
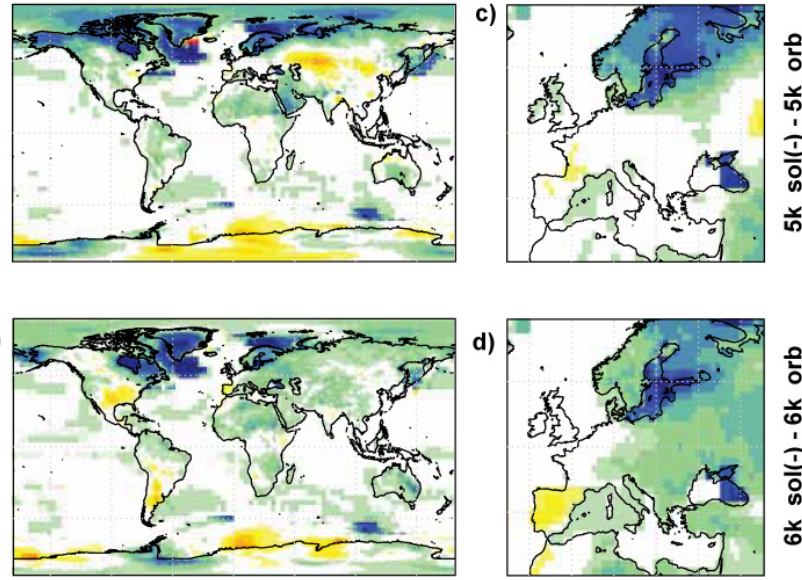

d)

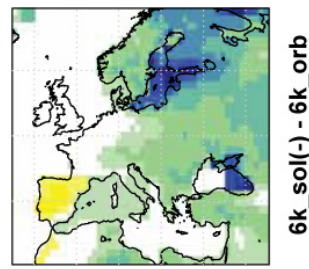

e)
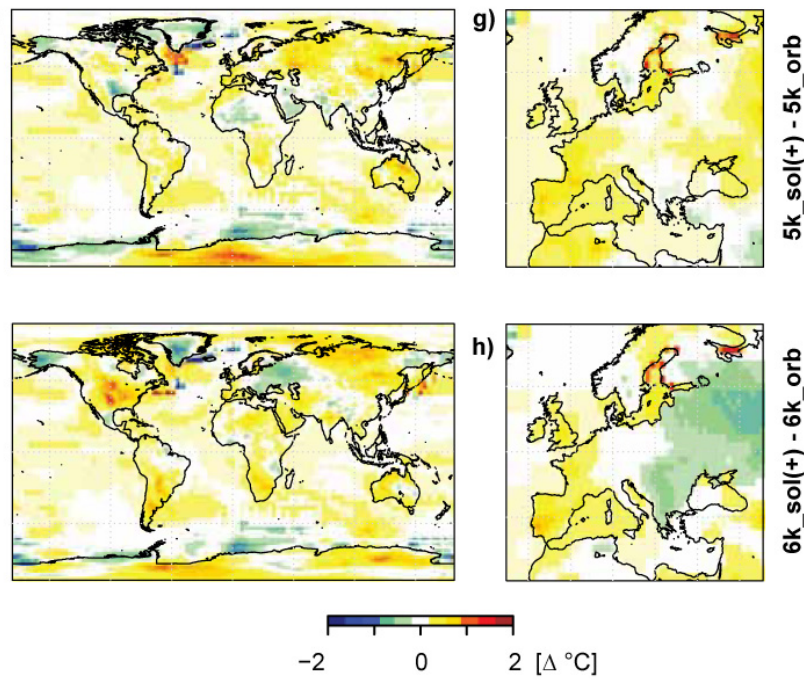

Fig. 6. Simulated solar activity-induced changes of mid-Holocene $(5 \mathrm{k}, 6 \mathrm{k})$ surface temperatures. The temperature anomalies are calculated between the experiment with additional solar influence boundary conditions (sol(-) and $\operatorname{sol}(+)$, respectively) and the undisturbed $5 \mathrm{k}$ and $6 \mathrm{k}$ climate simulations. Results for low solar activity forcing are shown in panels (a-d), and for high solar activity in panels (e-f). Plot details are similar to Fig. 2.

\section{Discussion}

In the following discussion we focus on two questions: (1) how strong is the linkage between temperature and $\delta^{18} \mathrm{O}$ variations for Holocene changes of orbital parameters and solar activity? (2) How large is the impact of the two forcing mechanisms on past atmospheric circulation changes over Europe?

\subsection{Holocene temperature and $\delta^{18} \mathrm{O}$ changes}

The oxygen isotope composition of an atmospheric water mass is altered by every phase change of the water. As a

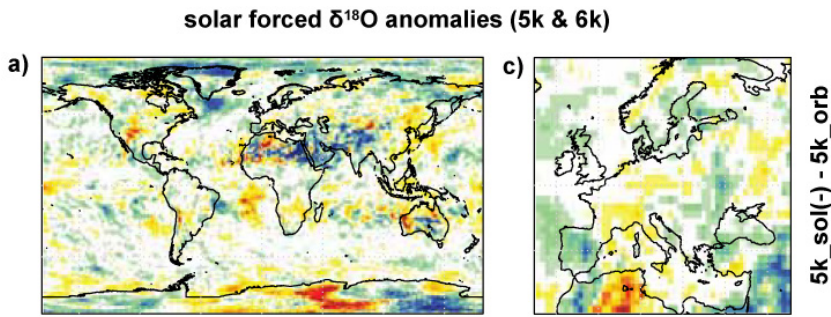

b)
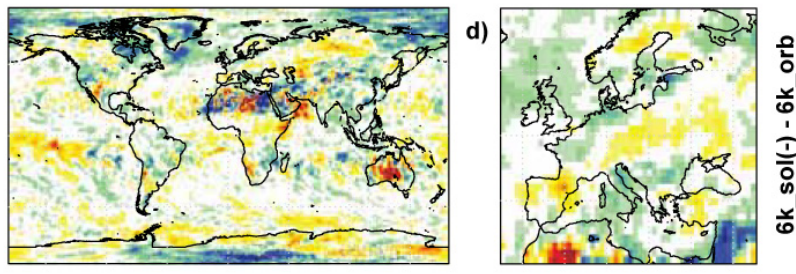

e)
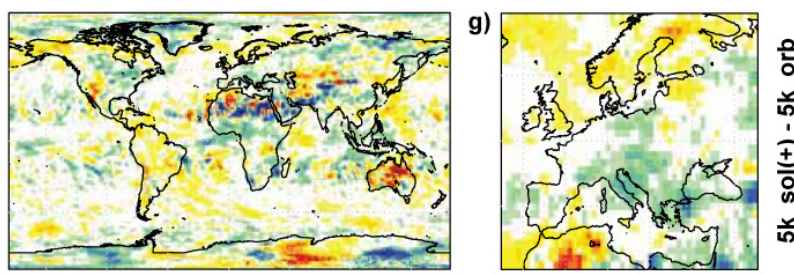

f)
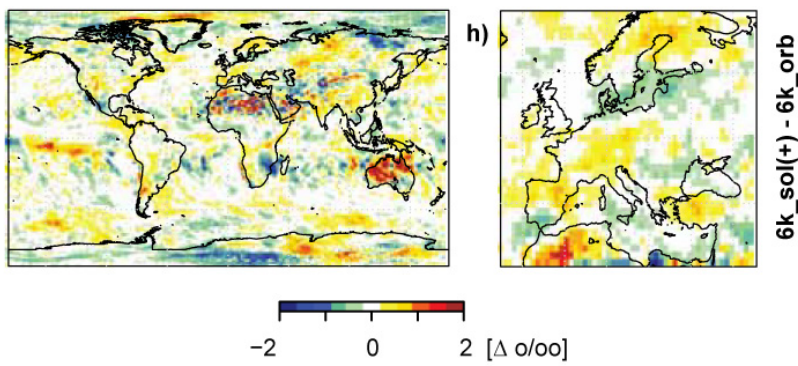

$2[\Delta \mathrm{o} / 00]$

Fig. 7. Same as Fig. 6 but for $\delta^{18} \mathrm{O}$ in precipitation values.

consequence, the final isotopic composition of precipitation reaching the Earth's surface is determined by several factors: the isotopic composition of the initial water source, temperature and climate conditions during evaporation, mixing and partial rainout of the water during its transport, as well as temperature and precipitation amount at the precipitation location. Despite this complexity, it is well known since the early work by Dansgaard (1964) that spatial variations of local temperature and $\delta^{18} \mathrm{O}$ in precipitation can be linked for many mid- and high-latitude regions of the Earth. Many isotope-enabled AGCMs can reproduce this temperature$\delta^{18} \mathrm{O}$ relation both on the global as well as on a regional scale (see Sturm et al., 2010, for more details on this topic). This strong spatial temperature- $\delta^{18} \mathrm{O}$ linkage has also been shown for present-day ECHAM5-wiso simulations, both on a global and European scale (Werner et al., 2011; Langebroek et al, 2011). 
orbital and solar forced surface temperature anomalies (5k \& 6k)

a)

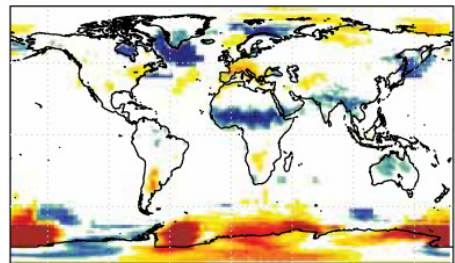

b)

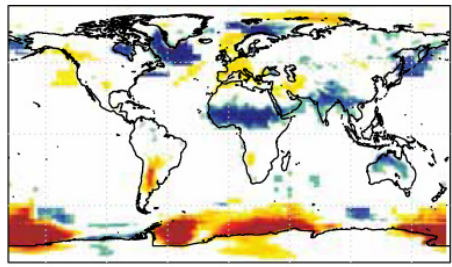

e)

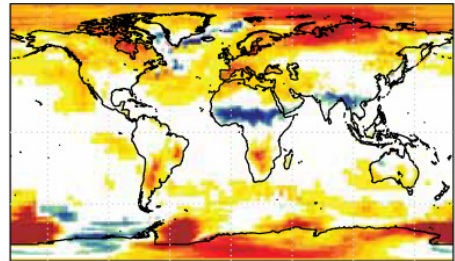

f)

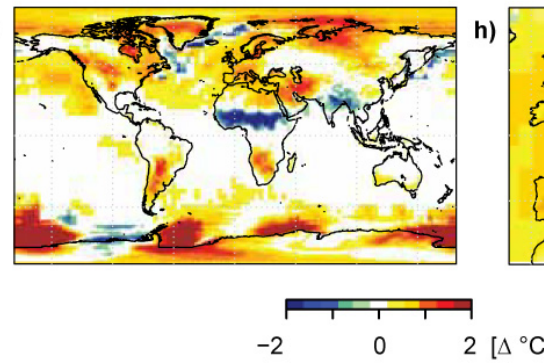

Fig. 8. Same as Fig. 6 but for the combined effect of orbital-driven insolation and solar activity changes.

For Europe, the temperature effect on $\delta^{18} \mathrm{O}$ is superimposed by the so-called continental effect, a combination of both progressive cooling as well as progressive rainout of eastward-advected moisture-bearing air masses as they traverse a continent (Lachniet, 2009). The latter describes an observed west-east gradient in $\delta^{18} \mathrm{O}$ with a decreasing isotope composition over Europe. This continental effect is not only found in present-day observations, but also in different Holocene isotope records, e.g. a collection of European speleothems (McDermott et al., 2011).

In general, long-term changes of isotopic composition of precipitation over mid- and high-latitude regions closely follow long-term changes of surface air temperature (Rozanski et al., 1992). However, for temporal changes of $\delta^{18} \mathrm{O}$, a clear correspondence of temperature and isotope variations does not always exist. For the present-day climate numerous studies (e.g. Noone and Simmonds, 2002; Werner and Heimann,

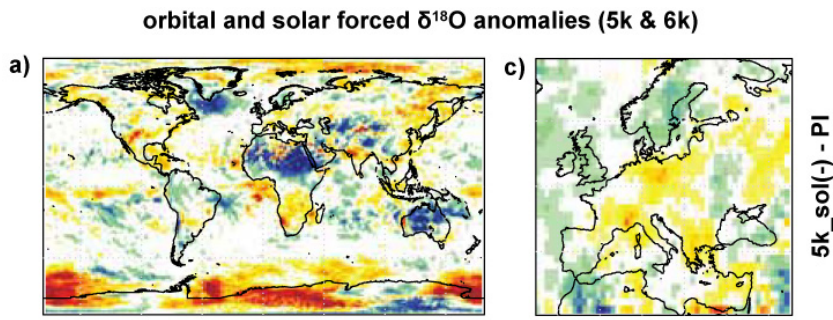

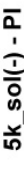

b)

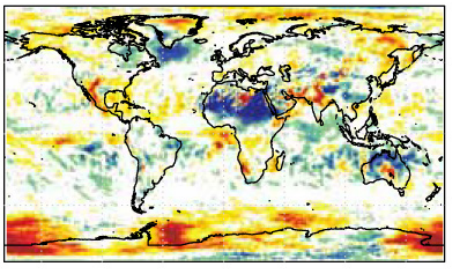

e)

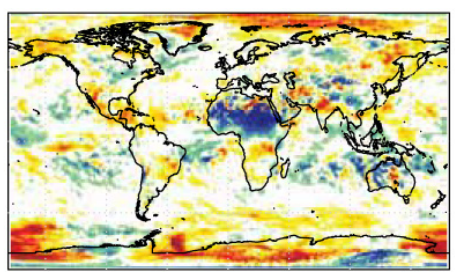

f)
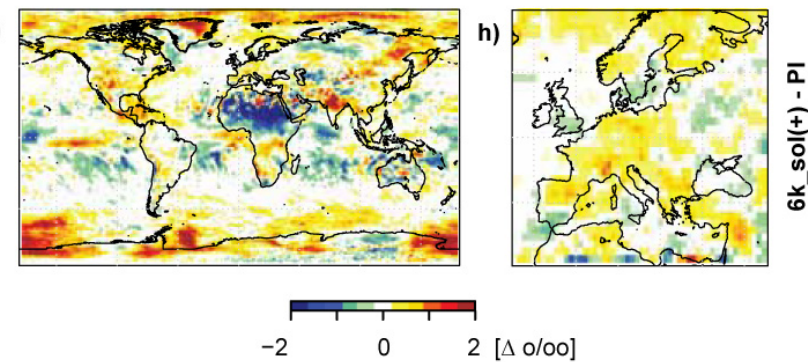

$2[\Delta \mathrm{o} / 00]$

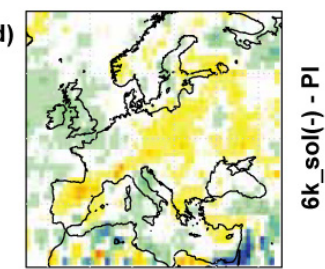

Fig. 9. Same as Fig. 8 but for $\delta^{18} \mathrm{O}$ in precipitation values.

2002; Schmidt et al., 2007; Herold and Lohmann, 2009; Pfahl et al., 2012; Field, 2010) have shown that changes of $\delta^{18} \mathrm{O}$ in precipitation often do not correspond well with local temperature changes. The isotopic signal is rather influenced by atmospheric circulation changes, which do not alter surface temperatures at the precipitation site in a comparable manner.

For the Holocene climate, LeGrande and Schmidt (2009) come to a similar conclusion. They have systematically analyzed the simulated isotopic composition of precipitation for eight different Holocene time slices using the GISS ModelE-R. According to their findings, Holocene changes of the isotopic composition of precipitation should better be interpreted in terms of regional hydrological cycle changes rather than as indicators of local climate.

The simulated spatial temperature and $\delta^{18} \mathrm{O}$ patterns by LeGrande and Schmidt (2009) are quite similar to our simulations (Figs. 2 and 3). Anomalies of the mid-Holocene (6k) 


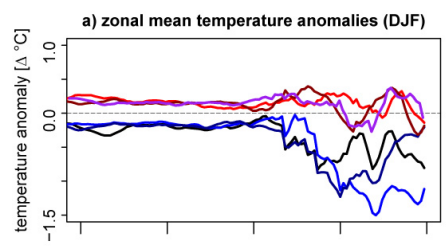

b) zonal mean temperature anomalies (JJA)
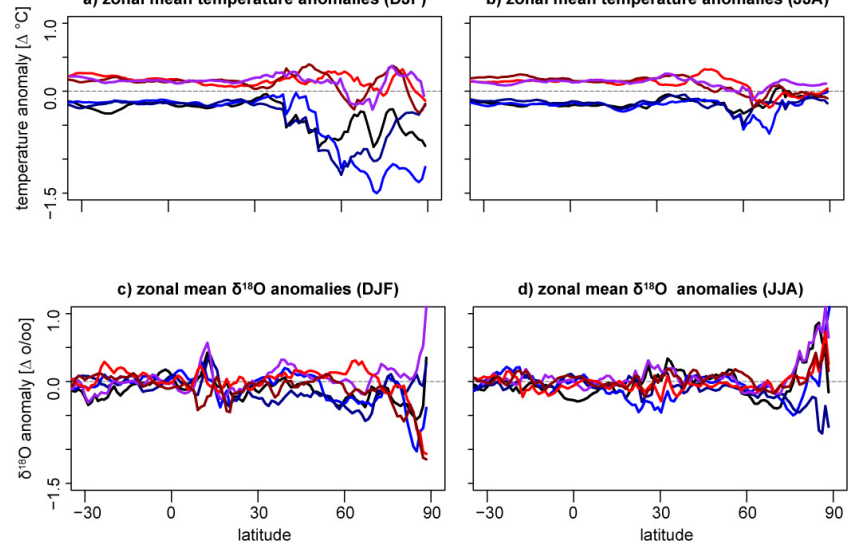

Legend: $\quad-$ solar minus (PI) - solar minus ( $5 \mathrm{k})-$ solar minus (6k)

Fig. 10. Zonal mean temperature and $\delta^{18} \mathrm{O}$ precipitation anomalies during boreal summer (JJA) and winter (DJF) due to changes in solar activity (see text). Redish lines visualize the influence of an increased solar activity, bluish lines represent a weak activity of the sun.

compared to PI show high-latitude warming and low latitude cooling according to orbital forcing. This pattern is accompanied by changes in $\delta^{18} \mathrm{O}$ following the conventional paleothermometer approach (Jouzel, 1999; Lachniet, 2009). In Europe, however, mid-Holocene warming is in both models accompanied by a relative depletion of $\delta^{18} \mathrm{O}$ values in the modelled precipitation. These patterns remain as a robust feature in both models. $\delta^{18} \mathrm{O}$ anomalies are in general more similar than temperature differences, e.g. LeGrande and Schmitt (2009) found more significant cooling in low latitudes, which remains insignificant in our simulations.

Our mid- and late Holocene results with solar activityinduced forcing, only, show little influence of local temperature changes on the isotopic composition of meteoric water, both on a global as well as on a regional scale (Figs. 4-7). For Holocene temperature changes, the model results consistently show a much stronger response to an assumed decrease in solar activity than to an increase for all three time slices investigated (Figs. 4 and 6). This is remarkable as the applied SST and SIC anomaly fields derived from the EGMAM simulation have the same pattern and magnitude, but opposite sign for the case of increased or decreased solar activity. For $\delta^{18} \mathrm{O}$, a similar asymmetry between the $\operatorname{sol}(-)$ and $\operatorname{sol}(+)$ simulations is partially detected in northern high-latitude regions.

For the mid-Holocene climate, the differences in orbital forcing between the $5 \mathrm{k}$ and $6 \mathrm{k}$ are rather low and lead to minor, but consistent differences in the $\delta^{18} \mathrm{O}$ signal (Fig. 2). However, if an additional solar activity-induced forcing is applied (Fig. 8), the resulting changes in $\delta^{18} \mathrm{O}$ pattern between $5 \mathrm{k}$ and $6 \mathrm{k}$ are not consistent any longer: In high northern latitudes, the effect of a decreased solar activity is stronger dur- solar forced $\delta^{18} \mathrm{O}$ anomalies (DJF) (a)

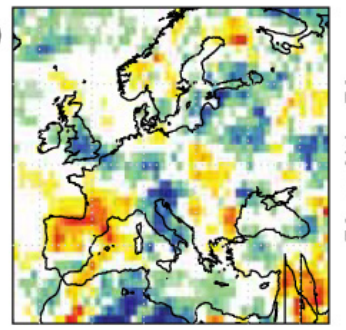

(b)

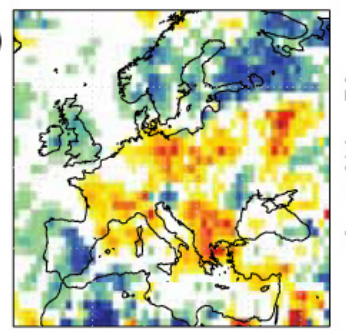

(c)

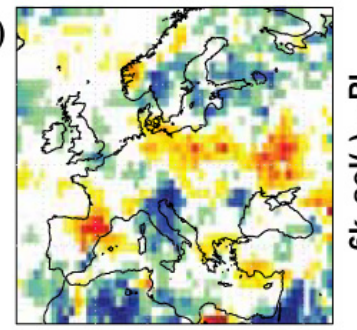

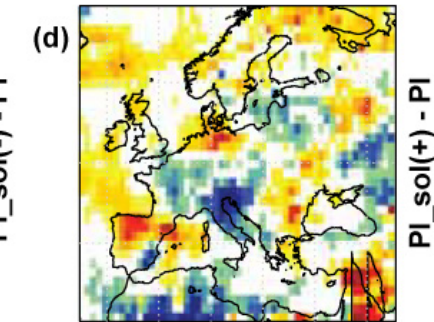

(e)

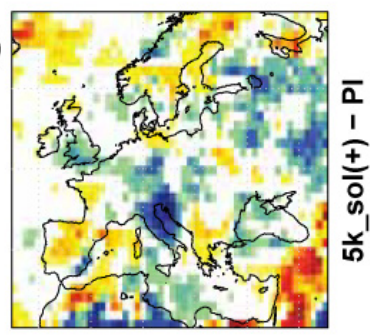

(f)

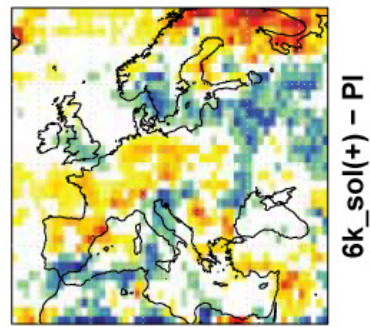

$2[\Delta \mathrm{o} / \mathrm{oo}]$
Fig. 11. Combined orbital-driven insolation and solar activityinduced winter (DJF) $\delta^{18} \mathrm{O}$ anomalies for PI, $5 \mathrm{k}$, and $6 \mathrm{k}$. The left column (a-c) shows simulation results for weak solar activity, the right column (d-f) for high solar activity.

ing $5 \mathrm{k}$ than during $6 \mathrm{k}$. This is noteworthy as the applied SST and SIC changes have been identical in both experiments.

We conclude from our simulation results that non-linear effects and feedbacks of the orbital and solar activity forcing substantially alter the $\delta^{18} \mathrm{O}$ in precipitation pattern and its relation to temperature changes. As some of the strongest temperature and $\delta^{18} \mathrm{O}$ changes occur in northern high-latitude regions, sea ice feedbacks might account for part of this nonlinear behavior. As sea surface temperatures in the polar regions are near the threshold of freezing (around $-1.8^{\circ} \mathrm{C}$ ) little cooling is required for sea ice formation. The occurrence of sea ice in a region, which was previously characterized by open seawater, leads to strong changes of surface albedo, near-surface temperatures and sea level pressure. 
In our experiments the largest response to changes in the North Atlantic sea ice cover are placed south of Greenland and the Labrador Sea. Here, strong cooling is consistently observed in the ECHAM5-wiso simulations with SST and SIC anomalies related to reduced solar activity. The counterpart experiments, where an increased solar activity is assumed, show only minor warming in these regions. Our results are in agreement with the reported simulations results of both models used to compile our boundary conditions to force ECHAM5-wiso. In the transient EGMAM simulation, a strong cooling over the western North Atlantic has been detected and related to an increase in sea ice and a salinity anomaly (Spangehl et al., 2010). In the Holocene ECHO-G experiment, increased eastward wind pattern occur during $6 \mathrm{k}$ relative to the PI climate, which enhance southward sea ice transport along the eastern coast of Greenland resulting in an increased sea ice concentration and a temperature drop south of Greenland (Lorenz and Lohmann, 2004). The combination of the SST and SIC anomalies derived from both these experiments has led to an amplification of this effect in our simulation, in particular during the winter months. All ECHAM5-wiso simulations with an assumed decrease in solar activity consistently show a larger influenced area with more sea ice in the Northern Hemisphere in comparison to the simulations with increased solar activity and less sea ice (not shown). This leads to a stronger effect on simulated surface temperatures and $\delta^{18} \mathrm{O}$ changes in the case of decreased solar activity in comparison to the one with increased activity.

Although a sea ice feedback might explain the simulated $\delta^{18} \mathrm{O}$ changes in the northern high latitudes, such feedback cannot account for simulated changes of $\delta^{18} \mathrm{O}$ in precipitation in other regions, e.g. most simulations show a slight isotopic enrichment over the southwestern part of North America. Over Australia, strong isotope enrichment is detected in three out of four mid-Holocene simulations with solar activity-induced forcing fields, only (Fig. 7a, b, e, f). Further analyses beyond the scope of this study are required to explain these simulated changes in $\delta^{18} \mathrm{O}$.

\subsection{Past atmospheric circulation changes over Europe}

Earlier studies based on both data analyses (Baldini et al., 2008; Wackerbarth et al., 2010) and model experiments (Field, 2010; Langebroek et al., 2011) suggest that the winter climate dominates the $\delta^{18} \mathrm{O}$ signal in precipitation in central Western Europe. The previous model studies demonstrated that the annual $\delta^{18} \mathrm{O}$ values are a combination of a strong winter and a weak summer signal. Since evapotranspiration of soil water is enhanced during summer (Trenberth, 1999), the recharge rate of the karst water that may enter any underlying cave system is much lower in summer than winter (Wackerbarth et al., 2010).

For the present-day climate, changes of the winter dominated signal can be linked to a NAO/AO-like pressure pat-

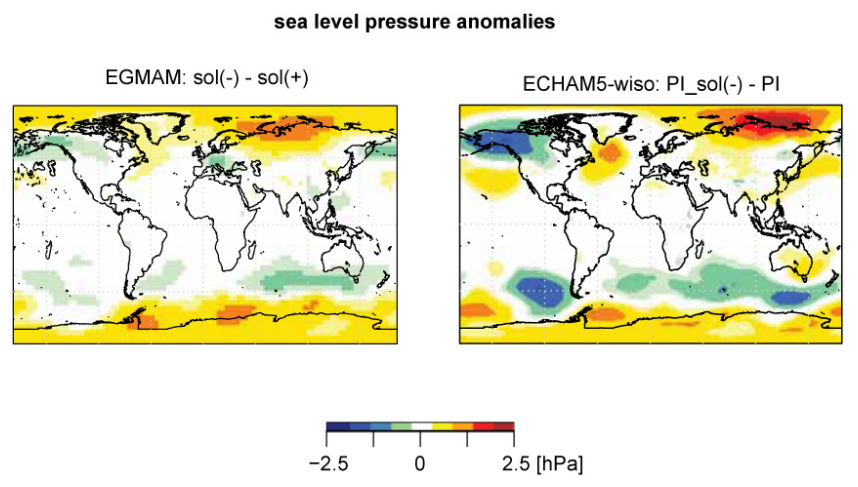

Fig. 12. The simulated annual mean sea level pressure pattern (SLP) of (a) the EGMAM experiment (after Spangehl et al., 2009) and (b) the corresponding ECHAM5-wiso simulations. Shown are the anomalies between a phase with low solar activity, sol(-), and a phase of default solar activity. This is the sol $(+)$ phase in the case of EGMAM, which is derived from a period with pre-industrial conditions (see Sect. 2.2), and the pre-industrial climate (PI) in the case of ECHAM5-wiso.

tern, which dominates European winter temperatures and $\delta^{18} \mathrm{O}$ values (Baldini et al., 2008; Field, 2010). In agreement with these findings, Langebroek et al. (2011) showed for a present-day ECHAM5-wiso simulation that $\delta^{18} \mathrm{O}$ precipitation values at the Bunker Cave location can be correlated to large-scale sea level pressure fields with a strong projection onto the NAO relation with temperature, but with an eastward shift of the northern center of action.

Boreal winter insolation due to orbital parameter variations did not change very much from mid- to late Holocene. However, different proxy data indicate a trend from a more positive phase of the NAO/AO during the mid-Holocene to a more negative one during the late Holocene (Rimbu et al., 2003, 2004). This is consistent with findings from the transient ECHO-G experiment, which we have used to derive our SST and SIC boundary fields. The ECHO-G simulation displays a change in the mean state of the NAO/AO and associated high-latitude temperature and sea ice changes during the Holocene (Lorenz and Lohmann, 2004).

For solar activity variations, previous investigations show a subtle influence on European winter circulation in reanalysis (Lockwood et al., 2010; Woollings et al., 2010) and longterm instrumental (Lohmann et al., 2004) data. Lohmann et al. (2004) show a blocking-like circulation for boreal winter and low solar activity, in line with Woollings et al. (2010) who report on a statistically significant higher frequency of cold winters is associated with a low solar activity. Further studies have shown negative phases of NAO-like pattern during periods with a less active sun (Martin-Puertas et al., 2012; Rimbu et al., 2004; Scholz et al., 2012; Trouet et al., 2009).

Our modeling results also suggest that a solar activityinduced forcing can alter the atmospheric circulation in the Northern Hemisphere. Sea level pressure anomalies 
simulated by our PI_sol(-) experiment are similar to those found in the EGMAM simulation of Spangehl et al. (2010) that explicitly includes stratospheric short-wave heating (Fig. 12). Both ECHAM5-wiso and EGMAM simulations cover similar conditions that resemble the anomaly between a pre-industrial period with a low solar activity (e.g. the Maunder Minimum) and a succeeding pre-industrial climate period with a high solar activity. It is noteworthy that our ECHAM5-wiso simulation can reproduce these SLP anomalies of the transient EGMAM experiment by prescribing related SST and SIC anomalies, only. These model results indicate that low solar activity might lead to a negative phase of a NAO-like pattern for a mean pre-industrial climate.

For both $5 \mathrm{k}$ and $6 \mathrm{k}$ mid-Holocene periods, our simulations with a combined orbital and solar activity-induced forcing result in atmospheric circulation patterns that show large differences between the simulated periods (not shown). Similar to the simulated temperature and $\delta^{18} \mathrm{O}$ values, we find a non-consistent, non-linear impact of the additional solar forcing on the simulated sea level pressure fields. Unfortunately, proxy data of Holocene atmospheric circulation changes is very rare, which hampers a more detailed evaluation of these model results.

\section{Concluding remarks}

The influence of orbital-driven insolation and solar activity changes on the distribution of stable water isotopes in meteoric precipitation is investigated for the mid- and late Holocene. In particular, we have analyzed different time slice experiments with sea surface temperature and sea ice boundary conditions perturbed by both orbital parameter and solar activity-induced changes. All experiments were calculated with the isotope-enhanced AGCM ECHAM5-wiso (Werner et al., 2011).

According to our model experiments, both orbital as well as solar forcing lead to alterations of similar amplitude of $\delta^{18} \mathrm{O}$ in precipitation. Changes of the orbital configuration lead to isotopic changes at mid- and high latitudes, which are in correspondence with the simulated variations of local surface temperatures. Only little changes are simulated between the two mid-Holocene periods, 6000 and $5000 \mathrm{yr}$ ago. However, this temperature-isotope relation diminishes if an additional solar activity-induced forcing is applied. The distribution of $\delta^{18} \mathrm{O}$ in precipitation becomes more random and does not show a clear correlation to surface temperatures any longer. As a consequence perturbations by additional solar forcing are able to change even the sign of overall $\delta^{18} \mathrm{O}$ anomaly patterns, in particular over Europe. This non-linear result of a combined orbital plus solar activity-induced forcing might explain some of the complex variability in $\delta^{18} \mathrm{O}$ observed in various Holocene proxy records.
Our model results indicate that a simple relation between local changes of surface temperatures and measured $\delta^{18} \mathrm{O}$ changes cannot be safely assumed a priori for the Holocene.

\section{Supplementary material related to this article is available online at: http://www.clim-past.net/9/13/2013/ cp-9-13-2013-supplement.pdf.}

Acknowledgements. We thank two anonymous reviewers who helped significantly improve the clarity of the manuscript and Augusto Mangini for his thoughtful editorial comments. We acknowledge financial supported via the DFG Research Unit 668 ("DAPHNE - Dated speleothems archives of the paleoenvironment") funded by the Deutsche Forschungsgemeinschaft (Bonn, Germany).

Edited by: A. Mangini

\section{References}

Baldini, L. M., McDermott, F., Foley, A. M., and Baldini, J. U. L.: Spatial variability in the European winter precipitation delta $\delta^{18} \mathrm{O}-\mathrm{NAO}$ relationship: Implications for reconstructing NAOmode climate variability in the Holocene, Geophys. Res. Lett., 35, L04819, doi:10.1029/2007g1032027, 2008.

Beer, J., Vonmoos, M., and Muscheler, R.: Solar Variability Over the Past Several Millennia, Space Sci. Rev., 125, 67-79, doi:10.1007/s11214-006-9047-4, 2006.

Dansgaard, W.: Stable isotopes in precipitation, Tellus, XVI, 436468, 1964.

Davis, B. A. S. and Brewer, S.: Orbital forcing and role of the latitudinal insolation/temperature gradient, Clim. Dynam., 32, 143165, doi:10.1007/s00382-008-0480-9, 2008.

Field, R. D.: Observed and modeled controls on precipitation $\delta^{18} \mathrm{O}$ over Europe: From local temperature to the Northern Annular Mode, J. Geophys. Res., 115, D12101, doi:10.1029/2009JD013370, 2010.

Fleitmann, D., Burns, S. J., Mudelsee, M., Neff, U., Kramers, J., Mangini, A., and Matter, A.: Holocene forcing of the Indian monsoon recorded in a stalagmite from southern Oman, Science, 300, 17379, 10.1126/science.1083130, 2003.

Fohlmeister, J., Schröder-Ritzrau, A., Scholz, D., Spötl, C., Riechelmann, D. F. C., Mudelsee, M., Wackerbarth, A., Gerdes, A., Riechelmann, S., Immenhauser, A., Richter, D. K., and Mangini, A.: Bunker Cave stalagmites: an archive for central European Holocene climate variability, Clim. Past, 8, 1751-1764, doi:10.5194/cp-8-1751-2012, 2012.

Fricke, H. C. and O'Neil, J. R.: The correlation between ${ }^{18} \mathrm{O} /{ }^{16} \mathrm{O}$ ratios of meteoric water and surface temperature: its use in investigating terrestrial climate change over geologic time, Earth Planet. Sci. Lett., 170, 181-196, doi:10.1016/S0012821X(99)00105-3, 1999. 
Gray, L. J., Beer, J., Geller, M., Haigh, J. D., Lockwood, M., Matthes, K., Cubasch, U., Fleitmann, D., Harrison, G., and Hood, L.: Solar influences on climate, Reviews on Geophysics, Rev. Geoph, 48, RG4001, doi:10.1029/2009RG000282, 2010.

Haigh, J. D.: The role of stratospheric ozone in modulating the solar radiative forcing of climate, Nature, 370, 1989-1991, doi:10.1038/370544a0, 1994.

Haigh, J. D.: The effects of solar variability on the Earth's climate, Phil. Trans. R. Soc. Lond. A, 361, 95-111, doi:10.1098/rsta.2002.1111, 2003.

Haigh, J. D.: The Sun and the Earth's Climate, Living Rev. Solar Phys., available at: http://www.livingreviews.org/lrsp-2007-2, 4, 2007.

Haug, G. H., Hughen, K. A., Sigman, D. M., Peterson, L. C., and Röhl, U.: Southward Migration of the Intertropical Convergence Zone Through the Holocene, Science, 293, 1308, 10.1126/science.1059725, 2001.

Herold, M. and Lohmann, G.: Eemian tropical and subtropical African moisture transport: an isotope modelling study, Clim. Dynam., 33, 1075-1088, doi:10.1007/s00382-008-0515-2, 2009.

Hoffmann, G., Werner, M., and Heimann, M.: Water isotope module of the ECHAM atmospheric general circulation model: A study on timescales from days to several years, J. Geophys. Res., 103, 16871-16896, doi:10.1029/98JD00423, 1998.

Hurrell, J. W.: Decadal trends in the north atlantic oscillation: regional temperatures and precipitation., Science, 269, 676-679, doi:10.1126/science.269.5224.676, 1995.

Ineson, S., Scaife, A. A., Knight, J. R., Manners, J. C., Dunstone, N. J., Gray, L. J., and Haigh, J. D.: Solar forcing of winter climate variability in the Northern Hemisphere, Nat. Geosci., 4, 753-757, doi:10.1038/ngeo1282, 2011.

Jager, C. D.: Solar activity and its influence on climate, Neth. J. Geosci., 87, 207-213, 2008.

Joussaume, S., Sadourny, R., and Jouzel, J.: A general circulation model of water isotope cycles in the atmosphere, Nature, 311, 24-29, 1984.

Jouzel, J.: Calibrating the isotopic paleothermometer, Science, 286, 910-911, 1999.

Jouzel, J., Russell, G. L., Suozzo, R. J., Koster, R. D., White, J. W. C., and Broecker, W. S.: Simulations of the HDO and $\mathrm{H}_{2}^{18} \mathrm{O}$ Atmospheric Cycles Using the NASA GISS General Circulation Model: The Seasonal Cycle for Present-Day Conditions, J. Geophys. Res., 92, 14739-14760, 1987.

Kim, J., Rimbu, N., Lorenz, S., Lohmann, G., Nam, S., Schouten, S., Ruhlemann, C., and Schneider, R.: North Pacific and North Atlantic sea-surface temperature variability during the Holocene, Quaternary Sci. Rev., 23, 2141-2154, doi:10.1016/j.quascirev.2004.08.010, 2004.

Kuroda, Y. and Kodera, K.: Effect of Solar Activity on the Polarnight Jet Oscillation in the Northern and Southern Hemisphere Winter, J. Meteorol. Soc. Jpn., 80, 973-984, 2002.

Lachniet, M. S.: Climatic and environmental controls on speleothem oxygen-isotope values, Quaternary Sci. Rev., 28, 412-432, doi:10.1016/j.quascirev.2008.10.021, 2009.

Laepple, T. and Lohmann, G.: Seasonal cycle as template for climate variability on astronomical timescales, Paleoceanography, 24, PA4201, doi:10.1029/2008PA001674, 2009.

Langebroek, P. M., Werner, M., and Lohmann, G.: Climate information imprinted in oxygen-isotopic composition of precip- itation in Europe, Earth and Planet, Sci. Lett., 311, 144-154, doi:10.1016/j.epsl.2011.08.049, 2011.

Leduc, G., Schneider, R., Kim, J. H., and Lohmann, G.: Holocene and Eemian sea surface temperature trends as revealed by alkenone and $\mathrm{Mg} / \mathrm{Ca}$ paleothermometry, Quaternary Sci. Rev. 29, 989-1004, doi:10.1016/j.quascirev.2010.01.004, 2010.

LeGrande, A. N. and Schmidt, G. A.: Global gridded data set of the oxygen isotopic composition in seawater, Geophys. Res. Lett., 33, L12604, doi:10.1029/2006GL026011, 2006.

LeGrande, A. N. and Schmidt, G. A.: Sources of Holocene variability of oxygen isotopes in paleoclimate archives, Clim. Past, 5, 441-455, doi:10.5194/cp-5-441-2009, 2009.

Lockwood, M.: Solar Influence on Global and Regional Climates, Surveys in Geophysics, 33, 503-534, doi:10.1007/s10712-0129181-3, 2012.

Lockwood, M., Harrison, R. G. G., Woollings, T., and Solanki, S. K.: Are cold winters in Europe associated with low solar activity?, Environ. Res. Lett., 5, 024001, doi:10.1088/17489326/5/2/024001, 2010.

Lohmann, G., Rimbu, N., and Dima, M.: Climate signature of solar irradiance variations: analysis of long-term instrumental, historical, and proxy data. Int. J. Climatol., 24, 1045-1056, doi:10.1002/joc.1054, 2004.

Lohmann, G., Wackerbarth, A., Langebroek, P., Werner, M., Fohlmeister, J., Scholz, D., and Mangini, A.: Simulated European stalagmite record and its relation to a quasi-decadal climate mode Clim. Past Discuss., 8, 3513-3533, doi:10.5194/cpd8-3513-2012, 2012.

Lorenz, S. J. and Lohmann, G.: Acceleration technique for Milankovitch type forcing in a coupled atmosphere-ocean circulation model: method and application for the Holocene, Clim. Dynam., 23, 727-743, doi:10.1007/s00382-004-0469-y, 2004.

Lorenz, S. J., Kim, J.-H., Rimbu, N., Schneider, R. R., and Lohmann, G.: Orbitally driven insolation forcing on Holocene climate trends: Evidence from alkenone data and climate modeling, Paleoceanography, 21, PA1002, doi:10.1029/2005PA001152, 2006.

Magny, M.: Holocene climate variability as reflected by midEuropean lake-level fluctuations and its probable impact on prehistoric human settlements: The record of Human/Climate interaction in Lake Sediments, Quatern. Int., 113, 65-79, doi:10.1016/S1040-6182(03)00080-6, 2004.

Martin-Puertas, C., Matthes, K., Brauer, A., Muscheler, R., Hansen, F., Petrick, C., Aldahan, A., Possnert, G., and Geel, B. V.: Regional atmospheric circulation shifts induced by a grand solar minimum, Nat. Geosci., 5, 397-401, doi:10.1038/NGEO1460, 2012.

McDermott, F., Atkinson, T. C., Fairchild, I. J., Baldini, L. M., and Mattey, D. P.: A first evaluation of the spatial gradients in $\delta^{18} \mathrm{O}$ recorded by European Holocene speleothems, Global Planet. Change, 79, 275-287, doi:10.1016/j.gloplacha.2011.01.005, 2011.

Noone, D. and Simmonds, I.: Associations between $\delta^{18} \mathrm{O}$ of water and climate parameters in a simulation of atmospheric circulation for 1979-1995, J. Climate, 15, 3150-3169, 2002.

Pfahl, S., Wernli, H., and Yoshimura, K.: The isotopic composition of precipitation from a winter storm - a case study with the limited-area model COSMOiso, Atmos. Chem. Phys., 12, 1629 1648, doi:10.5194/acp-12-1629-2012, 2012. 
Riechelmann, D. F. C., Schröder-Ritzrau, A., Scholz, D., Fohlmeister, J., Spötl, C., Richter, D. K., and Mangini, A.: Monitoring Bunker Cave (NW Germany): A prerequisite to interpret geochemical proxy data of speleothems from this site, J. Hydrol., 409, 682-695, doi:10.1016/j.jhydrol.2011.08.068, 2011.

Rimbu, N., Lohmann, G., Kim, J.-H., Arz, W., and Schneider, R.: Arctic/North Atlantic Oscillation signature in Holocene sea surface temperature trends as obtained from alkenone data, Geophys. Res. Lett., 30, 1045-1056, doi:10.1029/2002GL016570, 2003.

Rimbu, N., Lohmann, G., Lorenz, S. J., Kim, J. H., and Schneider, R. R.: Holocene climate variability as derived from alkenone sea surface temperature and coupled ocean-atmosphere model experiments, Clim. Dynam., 23, 215-227, doi:10.1007/s00382004-0435-8, 2004.

Rind, D.: The Sun's Role in Climate Variations, Science, 296, 673677, doi:10.1126/science.1069562, 2002.

Roeckner, E., Bäuml, G., Bonaventura, L., Brokopf, R., Esch, M., Giorgetta, M., Hagemann, S., Kirchner, I., Kornblueh, L., Manzini, E., Rhodin, A., Schlese, U., Schulzweida, U., and Tompkins, A.: The General Atmospheric Circulation Model Echam5 Part 1, Max Planck Institute for Meteorology, Report 349, Hamburg, Germany, 2003.

Roeckner, E., Brokopf, R., Esch, M., Giorgetta, M., Hagemann, S., Kornblueh, L., Manzini, E., Schlese, U., and Schulzweida, U.: Sensitivity of Simulated Climate to Horizontal and Vertical Resolution in the ECHAM5 Atmosphere Model, J. Climate, 19, 3771-3791, doi:10.1175/JCLI3824.1, 2006.

Rozanski, K., Araguás-Araguás, L. and Gonfiantini, R.: Relation between long-term trends of oxygen-18 isotope composition of precipitation and climate., Science, 258, 9815, doi:10.1126/science.258.5084.981, 1992.

Schmidt, G. A., LeGrande, A. N., and Hoffmann, G.: Water isotope expressions of intrinsic and forced variability in a coupled ocean-atmosphere model, J. Geophys. Res., 112, D10103, doi:10.1029/2006jd007781, 2007.

Scholz, D., Frisia, S., Borsato, A., Spötl, C., Fohlmeister, J., Mudelsee, M., Miorandi, R., and Mangini, A.: Holocene climate variability in North-Eastern Italy: potential influence of the NAO and solar activity recorded by speleothem data, Clim. Past Discuss., 8, 909-952, doi:10.5194/cpd-8-909-2012, 2012.

Shindell, D., Schmidt, G., Mann, M., Rind, D., and Waple, A.: Solar forcing of regional climate change during the Maunder Minimum, Science, 294, 2149-2152, doi:10.1126/science.1064363, 2001.

Solanki, S. K., Usoskin, I. G., Kromer, B., Schüssler, M., and Beer, J.: Unusual activity of the Sun during recent decades compared to the previous 11000 years., Nature, 431, 1084-1087, doi:10.1038/nature02995, 2004.

Spangehl, T., Cubasch, U., Raible, C. C., Schimanke, S., Körper, J., and Hofer, D.: Transient climate simulations from the Maunder Minimum to present day: Role of the stratosphere, J. Geophys. Res., 115, D00110, doi:10.1029/2009JD012358, 2010.
Steinhilber, F., Abreu, J. A., Beer, J., Brunner, I., Christl, M., Fischer, H., Heikkila, U., Kubik, P. W., Mann, M. E., McCracken, K. G., Miller, H., Miyahara, H., Oerter, H., and Wilhelms, F.: 9400 Years of Cosmic Radiation and Solar Activity From Ice Cores and Tree Rings, P. Natl. Acad. Sci, 109, 5967-5971, doi:10.1073/pnas.1118965109, 2012.

Sturm, C., Zhang, Q., and Noone, D.: An introduction to stable water isotopes in climate models: benefits of forward proxy modelling for paleoclimatology, Clim. Past, 6, 115-129, doi:10.5194/cp-6-115-2010, 2010.

Taylor, K. E., Williamson, D., and Zwiers, F.: The sea surface temperature and sea ice concentration boundary conditions for AMIP II simulations, Program for Climate Model Diagnosis and Intercomparison, Lawrence Livermore Natl. Lab., 60, 1-25, 2000.

Tindall J. C., Valdes, P. J., and Sime, L. C.: Stable water isotopes in HadCM3: Isotopic signature of El Niño, Southern Oscillation and the tropical amount effect, J. Geophys. Res.-Atmos., 114, D04111, doi:10.1029/2008JD010825, 2009.

Trenberth, K. E.: Atmospheric Moisture Recycling: Role of Advection and Local Evaporation, J. Climate, 12, 1368-1381, doi:10.1175/1520-0442(1999)012<1368:AMRROA > 2.0.CO;2, 1999.

Trouet, V., Esper, J., Graham, N. E., Baker, A., Scourse, J. D., and Frank, D. C.: Persistent positive North Atlantic oscillation mode dominated the Medieval Climate Anomaly, Science, 324, 78-80, doi:10.1126/science.1166349, 2009.

Wackerbarth, A., Scholz, D., Fohlmeister, J., and Mangini, A.: Modelling the delta $\delta^{18} \mathrm{O}$ value of cave drip water and speleothem calcite, Earth Planet. Sci. Lett., 299, 387-397, doi:10.1016/j.epsl.2010.09.019, 2010.

Wackerbarth, A., Langebroek, P. M., Werner, M., Lohmann, G., Riechelmann, S., Borsato, A., and Mangini, A.: Simulated oxygen isotopes in cave drip water and speleothem calcite in European caves, Clim. Past, 8, 1781-1799, doi:10.5194/cp-8-17812012, 2012.

Werner, M. and Heimann, M.: Modeling interannual variability of water isotopes in Greenland and Antarctica, J. Geophys. Res., 107, 4001, doi:10.1029/2001JD900253, 2002.

Wanner, H., Beer, J., Bütikofer, J., Crowley, T. J., Cubasch, U., Flückiger, J., Goosse, H., Grosjean, M., Joos, F., Kaplan, J. O., Küttel, M., Müller, S. A., Prentice, I. C., Solomina, O., Stocker, T. F., Tarasov, P., Wagner, M., and Widmann, M.: Mid- to Late Holocene climate change: an overview, Quaternary Sci. Rev., 27, 1791-1828, doi:10.1016/j.quascirev.2008.06.013, 2008.

Werner, M., Langebroek, P. M., Carlsen, T., Herold, M., and Lohmann, G.: Stable water isotopes in the ECHAM5 general circulation model: Toward high-resolution isotope modeling on a global scale, J. Geophys. Res., 116, D15109, doi:10.1029/2011JD015681, 2011.

Woollings, T., Lockwood, M., Masato, G., Bell, C., and Gray, L.: Enhanced signature of solar variability in Eurasian winter climate, Geophys. Res. Lett., 37, L20805, doi:10.1029/2010GL044601, 2010. 